\title{
Strong variations of weyl and browder type theorems for direct sums and restrictions
}

J. Sanabria, L. Vásquez, C. Carpintero, Ennis Rafael Rosas Rodriguez, O. García

\section{Abstract}

In this paper, we study the stability under direct sums and restrictions of some strong variations of Weyl and Browder type theorems recently introduced in Rashid and Prasad (Asia-Eur J Math 8:14, 2015. https://doi.org/10.1142/S1793557115500126), Sanabria et al. (Rev Colomb Mat 51(2):153171, 2017a, Acta Math Univ Comen (NS) 86(2):345-356, 2017b, Open Math 16(1):289-297, 2018).

Keywords:

Semi-Fredholm operator, Property (VE), Direct sums, Restrictions 